\title{
Valoración del punto de no retorno en el tiempo de elección bajo condiciones de incertidumbre en el pase en baloncesto
}

\author{
Assessment of the point of no return in choice reaction time \\ under uncertainty conditions in basketball pass
}

\author{
Quílez Maimón A. y Rojas Ruiz, F.J. \\ Departamento Educación Física y Deportiva. Facultad de Ciencias del Deporte. Universidad de Granada. Granada. España
}

\begin{abstract}
The purposes of this study in basketball pass were to analyse how uncertainty affects Reaction Times (RT) and to assess the Point of No Return (PoNR) in choice reaction times. 10 experienced basketball players participated. LEDs lights projected targets on screens. As LED was on, participants hit the target as fast as possible to measure their RT. In the second phase and during the pass Movement Time (MT), the target position could randomly shift to another spot at five instants with progressive delays depending on RT \& MT of each player. Results showed that uncertainty increases RT, but does not affect MT. As target change was delayed, neither RT nor MT changed but errors appeared. 2/5MT+RT defined PoNR, as errors soared from this point onwards. Further work is suggested to increase the study external validity and to define a training procedure to decrease both RTs \& errors under uncertainty conditions.

Keywords: basketball pass, uncertainty conditions, reaction times, point of no return, biomechanics
\end{abstract}

Resumen: Los objetivos del estudio fueron analizar como afectaba la incertidumbre a los Tiempos de Reacción (TR), y la evaluación del Punto de No Retorno (PdNR). Participaron diez jugadores experimentados. Se utilizaron LEDs para proyectar objetivos/targets en pantallas. Al encenderse el LED los participantes debían pasar hacia el objetivo/target lo más rápido posible para evaluar sus TRs. En la fase segunda y durante el Tiempo de Movimiento (TM) del pase el objetivo/target podía cambiar aleatoriamente a otra posición en cinco instantes con un retraso progresivo dependiendo del TR y TM de cada jugador. Los resultados indicaron que la incertidumbre incrementa TR, pero no afecta TM. Cuando se retrasó el cambio de objetivo/target, no cambiaron ni TR ni TM, pero aparecieron errores. El PdNR se determinó en 2/5TM+TR, dado que los errores se dispararon a partir de ahí. Se sugiere continuar el estudio para definir un entrenamiento que disminuya errores y TRs.

Palabras clave: pase en baloncesto, condiciones de incertidumbre, tiempos de reacción, punto de no retorno, biomecánica.

\section{Introduction}

Key basket actions are passing, dribbling and shooting; being the pass the second most requested action during the game (22\%) after dribbling action, and one of the most important technical action after shooting (Galatti, Paes, Machado, \& Seoane, 2015; Nunes et al., 2016; Oliver, 2006). This study focuses on the analysis of some key tactic aspects associated to the pass, namely how uncertainty conditions affect reaction times and errors rate.

Although there are some references in the literature for similar analysis applied to other sports, and specifically for fencing (Gutiérrez-Cruz, Rojas, \& Gutiérrez-Davila, 2016; Gutierrez-Davila, Rojas, Caletti, Antonio, \& Navarro, 2013b); to our knowledge this is the first time that an analysis like this is being performed for basketball.

According to Schmidt \& Lee (2011), Reaction Time (RT) is a measure of the time from the arrival of a suddenly presented and unanticipated signal to the beginning of the response to it, whilst Movement Time (MT) is defined as the

Dirección para correspondencia [Correspodence address]: Arturo Quilez Maimon. Paseo de las Huertas, 2 2F Almansa, (Albacete) C.P. 02640 E-mail: arturoquilez@gmail.com interval from the initiation of the response to the completion of the movement. The sum of RT and MT is termed Response Reaction Time (RRT).

Within the scope of the analysis performed under uncertainty conditions, the Point of No Return (PoNR) is defined by Osman, Kornblum, \& Meyer (1986) as the moment beyond which alterations to motor decisions cannot be made, at least not reliably, whilst uncertainty is associated with the likelihood that the course of events occurs as expected before initiating the movement sequence (Gutiérrez-Cruz et al., 2016).

Within this document, Choice Reaction Time (CRT) is defined as the time period from the target change in any experimental condition (stimulus) to the moment at which the player changes the trajectory of the ball towards the new target position (Gutiérrez-Dávila, Rojas, Antonio, \& Navarro, 2013a).

Once players have passed PoNR, there is not turning back. It means there is no a reliable option to change the ball trajectory into the new, distinct Target. As a result, errors suddenly increase for Target Change times at PoNR \& beyond. In the study, PoNR is found by analysing number of errors accumu- 
lated for each of the 5 scenarios defined to assess the impact of Uncertainty.

Following the study by Dodds (cited by Iglesias, Sanz, García-Calvo, Cervelló, \& Del Villar, 2005) it is suggested that skilled players at cognitive level are characterized by a more elaborated, structured, organized and sophisticated knowledge than new players. People who are trained in sports such as baseball and basketball need less reaction time than people who do not practice any sports regularly. Similarly Goh, Gordon, Sullivan, \& Winstein (2014) say that when a person responds several times to a choice-reaction test, they often reduce their response times.

Similarly, according to Pérez, Iglesias, \& Mendes (2008) the tactical decision also depends on factors such as reaction time, both physiological and mental conditions, and motor skills.

These inhibition processes associated to the presence of uncertainty are essential in the flexibility of responses in sports that require accuracy movements in environments where the conditions are unstable (Muggleton \& Brennan, 2010). Basketball is a particularly clear example of the importance of these cognitive processes, because of the fact that is increasingly important to modify scheduled actions in response to unexpected opponent actions or feints, whose response should be corrected through an intensive inhibition process (Borysiuk \& Waskiewicz, 2008; Di Russo, Taddei, Apnile, \& Spinelli, 2006; McGarry \& Franks, 2003).

The studies that have been carried out previously in this domain are mainly about fencing, but there is a huge lack of information in this field in the scientific literature for which concern sport teams in general, and basketball in particular.

According to the reference by Gutierrez-Davila et al. (2013), there is a significant increase in reaction time and choice reaction time once the uncertainty raises, whilst the movement time, the accuracy and the patterns sequence are not affected. Following a subsequent rehearsal by GutierrezDavila et al. (2013), it is known that when a decision is taken between two options, (i.e. there is a target change) RT, MT and time elapsed in acceleration phase of Centre of Mass (CM) are significatively increased compared to when only a single posibility is taken. In adittion, Gutiérrez-Cruz et al. (2016), show in their study that when the target change was delayed the technical execution of the lunge changed, leading to more errors.

In this study, the purpose is to apply the same situation as those previous studies but transferring the analysis to basketball pass as nothing has been found in this respect in the literature. Therefore, the twofold purposes of this study have been to analyse whether uncertainty affects response times, and secondly, to assess the PoNR in CRT under uncertainty conditions in basketball pass.
The main hypothesis is that when uncertainty increases, RRT is going to increase as well, and the more time elapsed in appearing the second stimulus (second LED light), the longer is going to take to the participants in their RRT as well as their number of mistakes is going to increase. We hope that the results obtained from the analysis performed in this study will pave the way towards the (future) definition of training methods aiming at the improvement of both reaction times and number of errors.

\section{Method}

\section{Participants}

This study included 10 male basketball players with more than 10 years of experience in federate competition at regional level (height $=1.82 \pm 0.07 \mathrm{~m}$; weight $=70.8 \pm 7.3 \mathrm{~kg}$; age $=25.7 \pm 7.9$ years). Written form consent was obtained from all participants in accordance with the guidelines of the University Ethics.

One $0.60 \times 0.37 \mathrm{~m}$ force plate (DINASCAN IBV, Instituto de Biomecánica de Valencia, Spain) set at $500 \mathrm{~Hz}$ was used. Placed side by side, the force plate registered the ground reaction force, as shown in Figure $13 \mathrm{D}$ motion capture system with a video camera set at $210 \mathrm{~Hz}$ (CASIO EXZR800) recorded the entire action. A projector connected to a computer projected a basketball image simulating a real action on a plastron. All systems were synchronised by an electronic signal. Figure 2 shows the set-up of the recording systems.

Figure 1. Graphical representation of the horizontal component of the force following the methodology proposed by Gutiérrez- Davila et al., (2013), a), the beginning of the movements is determined from the moment in which the horizontal net force component reaches a value greater or equal to $1 \%$ of the weight of the body of the player.

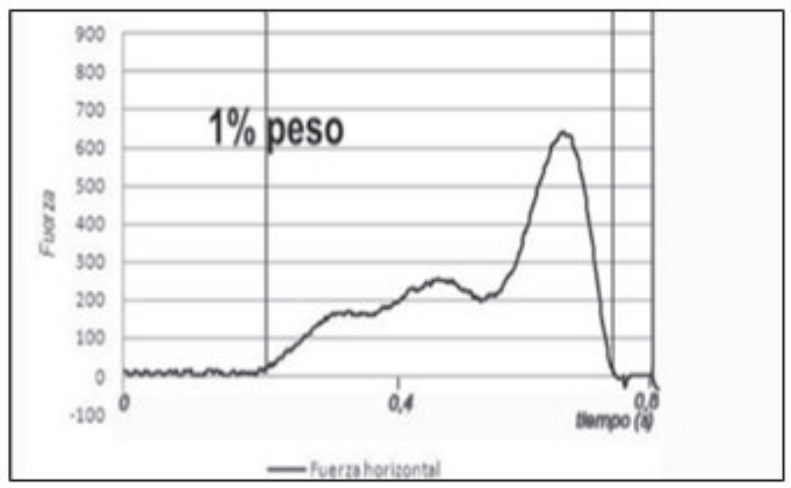


Figure 2. Schematic representation of the experimental set-up and recording systems.

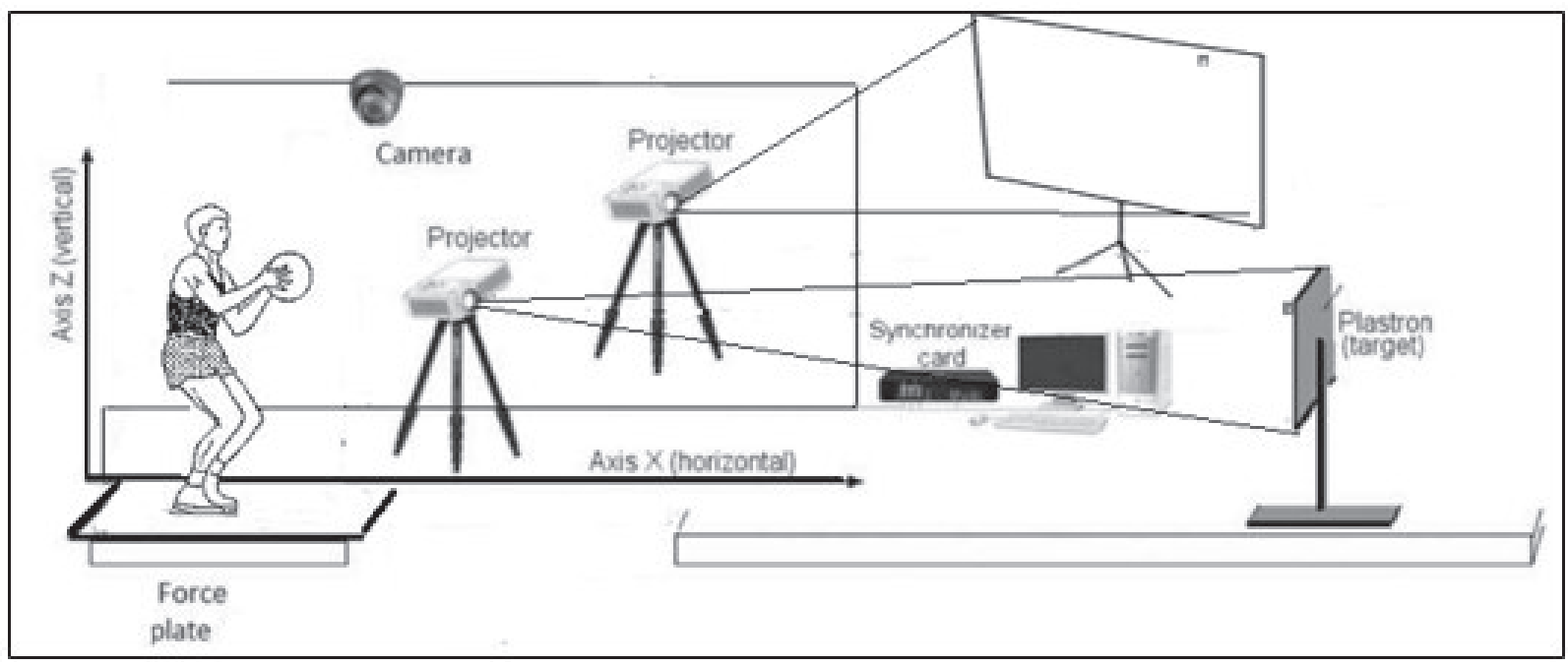

The field trial materials belong to the research group CTS362 Analysis of Human Movement of the University of Granada.

A video camera CASIO EX-ZR800 recorded the sagittal plane of motion at a frequency of $210 \mathrm{~Hz}$. An electronic signal was used for the synchronization between the platform and the two LED lights represented on screens Figure 3.

This electronic system allowed selecting the power of one of the two LED lights at the beginning of the record, which acts as a stimulus for the player to start performing the pass. This system was developed from the Arduino board, which is a free hardware platform based on a plate with a microcontroller, designed to facilitate the use of electronics in multidisciplinary projects.
Figure 3. Synchronism with LED lights turned on, whilst platform soles were recording.

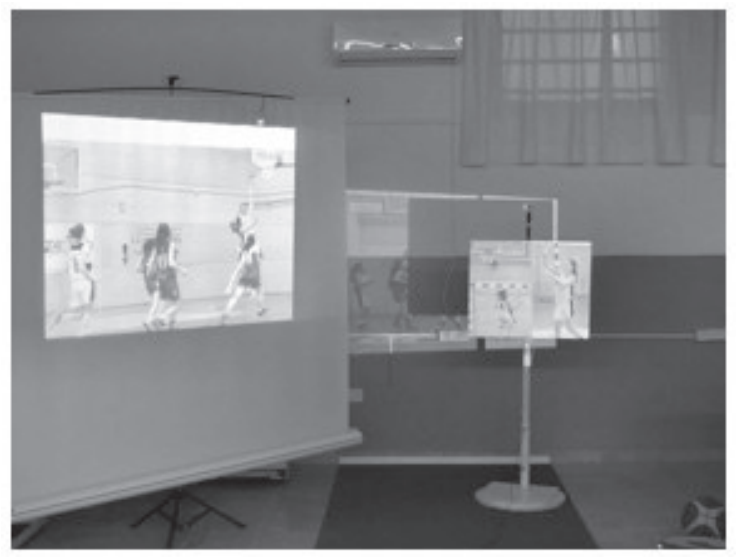

Figure 4. System formed based on the Arduino board.

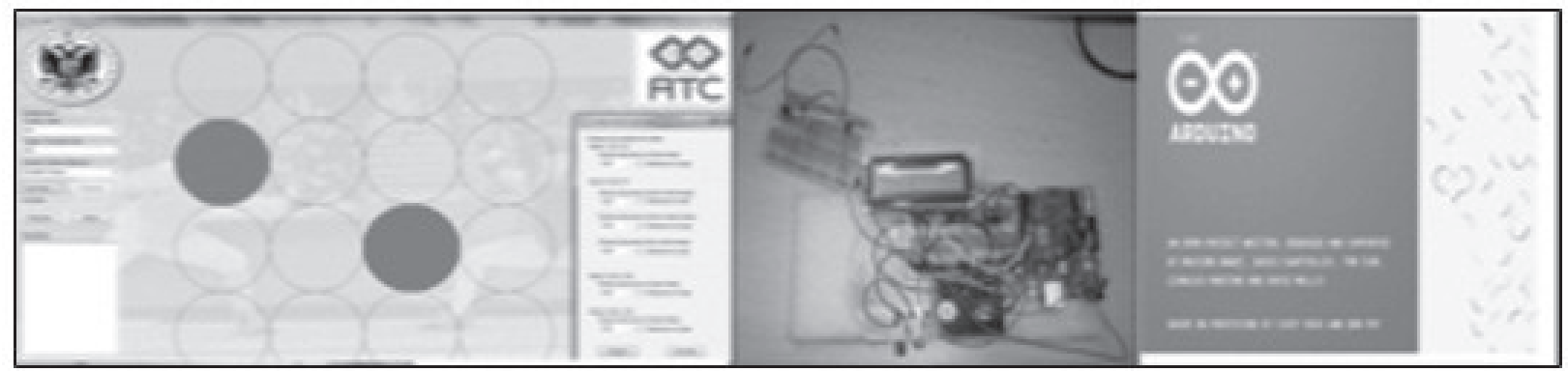

The hardware consists of a baseboard with an Atmel AVR microcontroller and input/output (I/O) ports; the input port has programming times to light up LED lights and the output port has a $5 \mathrm{~V}$ electronic signal which initiate the plat- form and synchronizes with LED lights, that are lighten up at scheduled intervals in milliseconds and a viewer time.

The software consists of a development environment that implements the Processing/Wiring programming and the boot 
loader that is executed on the baseboard. It is programmed into the baseboard computer to command the electronic components.

\section{Procedure}

The trial performed in this study has comprised two phases along time: In phase I (no uncertainty is considered), a first
LED light is used to trigger the stimulus for the participants in order to measure their reaction times. In phase II (the effects of uncertainty are incorporated in the analysis) two LED lights are used in sequence to generate two contradictory stimuli, as explained below.

Figure 5 shows the sequence operation of the two LED lights (stimuli) in the procedure followed during the trial.

Figure 5. Procedure followed.

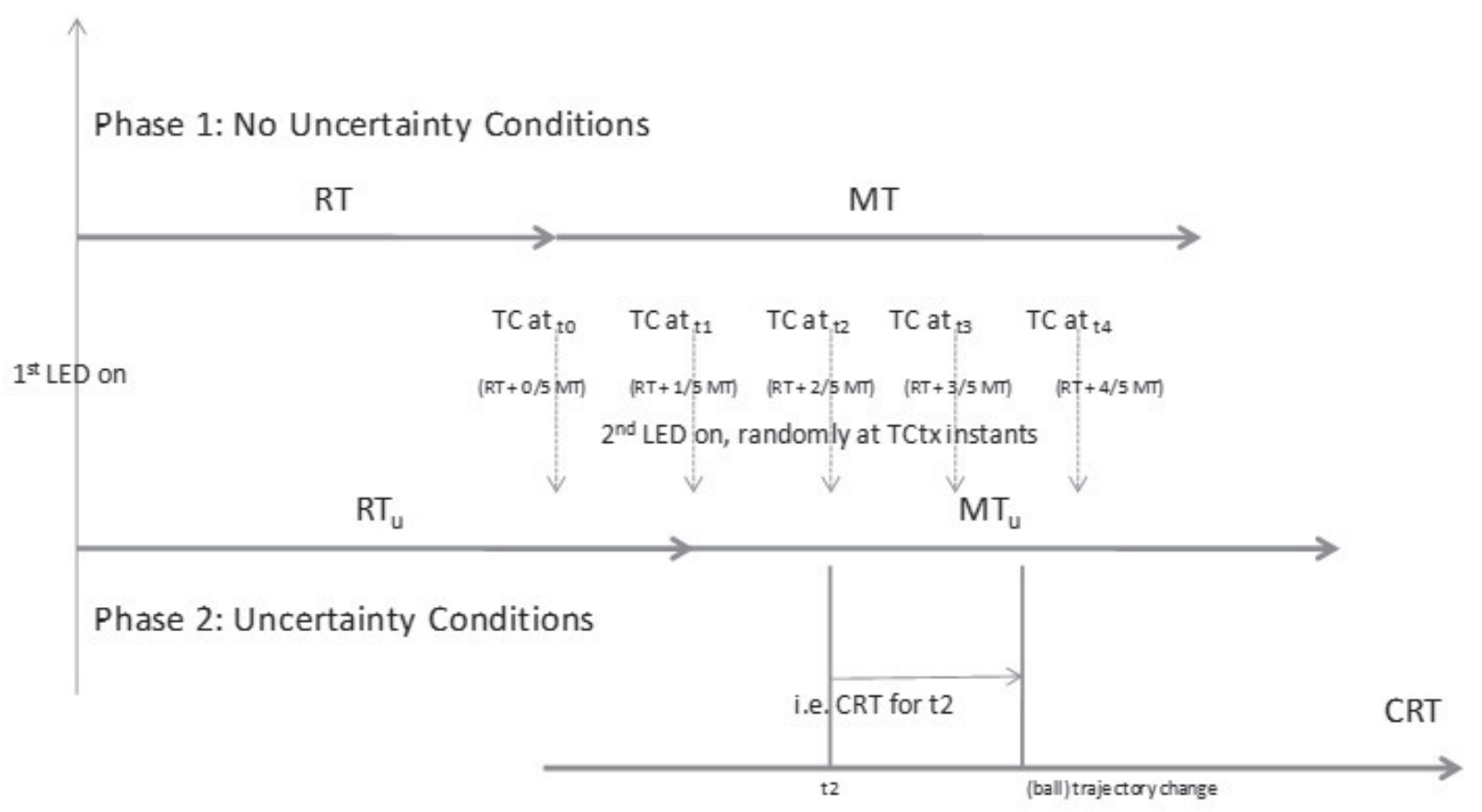

As mentioned above, in phase I and in order to measure these reaction times (RT, MT and RRT), a first LED light is used as a stimulus signal in the trial performed in this study. AS the stimulus appears (first LED is on) the player must perform a direct pass trying to reach as quickly as possible the destination.

In phase II and in order to incorporate the effect of uncertainty (reflected via inhibition processes), the counter order paradigm (Go/No Go) is used. It is based on answering two contradictory signals, initially with a first order (Go) followed by a counter order (No-Go), which is presented with a certain time delay with respect to the former. The first signal indicates to execute as quickly as possible an action (Go), in this trial it will be a pass, and the next action indicates to stop that old action as soon as possible (No-Go). In this study, the Go signal is turned on once the first LED light will light up, after which the player must perform a direct pass trying to reach as quickly as possible the destination. The No-Go signal will consist of detecting when the other, second LED light turns on slightly and randomly later in time, and the player must inhibit the first signal and operate with the second signal

First of all a pilot study was set up with an highly qualified expert in basketball (ACB level) to assure which technical procedure was best appropriate to carry out the field trial study. This first pilot study was focused on isolating the pass technic and assuring it as standard technic despite the level of the player who was adopting that technic, by doing this, a more controlled lab situation was assured, not leaving anything out of control. Once this pilot was done, the triple threat position was the one chosen and the experimental research design was ready.

In this study, as said before, participants adopted the triple threat position, which following Oliver (2006), is a basic ready, or athletic, stance that promotes a smooth transition into a quick, physical movement by the offensive player with possession of the (basket) ball.

After a specific 5 min warm-up with several trials to be- 
come familiarised with the system, the players received precise instructions for the task and positioned on the TripleThreat Position standing on the platform. Next, the position of the projection screen or plastron was adjusted according to the player's height, so that they could adjust their position to the plastron. After several trial passes to the plastron at the pre-established distance, players were allowed to make adjustments as necessary until finding a comfortable distance. Once adjustments were made, players were ready to undertake the trial.

Following the methodology of previous studies (Guiterrez-Cruz et al. 2015; Gutiérrrez-Dávila et al. 2013a;) at the command of "ready?" a first LED light was turned on where the ball should go to and all recording systems were activated, then, the player had to pass the ball to that point mentioned before, as fast as he could, whilst reaction response was recorded by the force platform. After several repetitions to become familiar with the experimental condition, players performed five valid trials. We considered the median of the five values registered. Failure to pass the ball outside the point was considered an error.

Reaction time was defined as the time elapsed from the appearance of the first LED light to the initiation of the movement. Initiation of the movement was defined as the moment at which the net force of the horizontal component $F_{X}$ reached a value $\geq 1 \%$ of the player's body weight. When reaction time was $<100 \mathrm{~ms}$, the trial was repeated. MT was calculated using the RRT registered by analysing the video recording with Kinovea (MT=RRT-RT).

Then, in the second phase trials where there could be a target change during the pass were performed. Thus, as in the previous condition, players positioned in Triple-Threat Position and executed a step-forward-pass as fast as possible when the first LED light appeared in the projector trying to pass to the reflected teammate player's hand. Before the response reaction was completed, there was another, second LED light, set $0,5 \mathrm{~m}$ aside from the projector, which could be lighted up or not in a randomly manner. For each specific participant, the five target change times $(\mathrm{t} 0, \mathrm{t} 1, \mathrm{t} 2, \mathrm{t} 3$ and $\mathrm{t} 4)$ were calculated adding to his reaction time, $0,1 / 5,2 / 5,3 / 5$ or $4 / 5$ of his movement time, respectively. The reaction time and movement time were based on the median values of response times and reaction times for the previous five valid trials performed in the previous phase. The five target change times served to define the five experimental conditions (TCT $(\mathrm{t} 0)$, TCT $(\mathrm{t} 1)$, TCT(t2), TCT(t3), TCT(t4)), as shown in Figure 5.

The players performed fake trials of each experimental condition where the second LED light did not light up, set by the investigator to avoid player's learning capacity. Finally, for each condition, only the trial with the median of the five RRT values was analysed.

Data were expressed as mean $(\mathrm{M})$ and standard deviations (SD) for each experimental variable and condition. To verify the reliability of the tests, a repeated-measures analysis of variance (ANOVA) was applied to all trials performed in the five experimental conditions (five trials for each condition) using response time as the dependent variable. No significant differences were found among the trials, and the intra-class correlation coefficient was high $(\mathrm{P}<0.001)$, between 0.536 and 0.947 for the five experimental conditions which were analysed. A repeated-measures ANOVA was used to evaluate significant differences among the conditions. Mean differences between experimental conditions and 95\% Confidence Interval (CI) were calculated. Effect size statistics was assessed using Cohen's d, taking into account the cut-off established by Cohen, 0.20. 0.50 and 0.80, thus reflecting small, medium, and large effect sizes, respectively (Nakagawa \& Cuthill, 2007). If a significant main effect was observed, least significant difference multiple-range tests determined where the differences occurred. Results were analysed using Statgraphics plus 5.1 software for Windows (STCS, Inc., Rockville, MD, USA).

\section{Results}

Table 1 shows the values for Reaction Time, Movement Time and Response Reaction Time without uncertainty and with uncertainty.

Reaction Time (RT) did change $(\mathrm{F}=25.2 ; \mathrm{p}=0.0001)$, increasing significantly; conversely, Movement Time (MT) did not significantly change affected by the uncertainty $(\mathrm{F}=0.04$; $\mathrm{p}=0.847$ ). Finally the Response Reaction Time (RRT) increased $(\mathrm{F}=5.7 ; \mathrm{p}=0.054)$.

Table 1. This table expresses Mean \pm SD of Reaction Time, Movement Time and Response Reaction Time in response of whether the trial had uncertainty or not.

\begin{tabular}{lccccc}
\hline & Without uncertainty & With uncertainty & Mean differences & & \\
Variables & Mean \pm SD & Mean \pm SD & Mean $\pm s$ & $95 \%$ CI & Effect size d \\
\hline Reaction Time, RT $(\mathrm{ms})$ & $215.3 \pm 46.7$ & $276.38 \pm 81.2^{* * *}$ & $-61.08 \pm 103$ & -90 to -31 & 0.9 \\
Movement Time, MT (ms) & $330.1 \pm 85.9$ & $325.5 \pm 88.9$ & $4.5 \pm 72$ & -46 to 56 & 0.1 \\
Response Reaction Time RRT (ms) & $543.8 \pm 94.9$ & $600.2 \pm 108.1^{*}$ & $48 \pm 70$ & -2 to 98 & 0.6 \\
\hline
\end{tabular}

Notes: ${ }^{* * *} \mathrm{P}<0.001 ;{ }^{* *} \mathrm{P}<0.01 ;{ }^{*} \mathrm{P}<0.05$; indicate significant differences between the groups $(\mathrm{P}<0.05)$. 
Secondly, to assess the Point of No Return (PoNR) once the time has been modified by the investigator (independent variable), neither Reaction Time $(\mathrm{F}=0.46 ; \mathrm{p}=0,767)$ nor Movement Time $(\mathrm{F}=2.42 ; \mathrm{p}=0.066)$ were affected when the target change was delayed, thus consequently Response Reaction Time did not have significant differences either $(\mathrm{p}=0.14)$.

Table 2. This table expresses Mean \pm SD of Reaction Time, Movement Time and Response Reaction Time in choice reaction time for the five experimental conditions of Phase II.

\begin{tabular}{cccc}
\hline Variables & $\begin{array}{c}\text { Reaction Time } \\
\text { Mean } \pm \text { SD }\end{array}$ & $\begin{array}{c}\text { Movement } \\
\text { Time } \\
\text { Mean } \pm \text { SD }\end{array}$ & $\begin{array}{c}\text { Response Reaction } \\
\text { Time } \\
\text { Mean } \pm \text { SD }\end{array}$ \\
\hline TCT-0 $(\mathrm{ms})$ & $280.1 \pm 77.7$ & $318.1 \pm 92.1$ & $598.1 \pm 119.2$ \\
TCT-1 $(\mathrm{ms})$ & $273.5 \pm 81.6$ & $401.5 \pm 185.7$ & $675.1 \pm 244.8$ \\
TCT-2 $(\mathrm{ms})$ & $286.6 \pm 75.9$ & $307.4 \pm 74.5$ & $594.2 \pm 72.4$ \\
TCT-3 $(\mathrm{ms})$ & $255.7 \pm 58.9$ & $318.9 \pm 70.6$ & $574.6 \pm 70.2$ \\
TCT-4 $(\mathrm{ms})$ & $286.2 \pm 115.6$ & $323.3 \pm 91.5$ & $609.3 \pm 118.9$ \\
\hline
\end{tabular}

Table 3 shows where there are significance results. There is strong evidence $(\mathrm{F}=8.04 ; \mathrm{p}=0.00001)$ that when the target change was delayed, errors strongly increase.

The method used to discriminate among the means is the procedure of least significant difference (LSD) Fisher.

Table 3. This table expresses significance results between different experimental conditions.

\begin{tabular}{lcc}
\hline Contrast & Sig. & Dif. \\
\hline TCT $(\mathrm{t} 1)-\mathrm{TCT}(\mathrm{t} 0)$ & & $-0,1$ \\
TCT $(\mathrm{t} 3)-\mathrm{TCT}(\mathrm{t} 4)$ & & 0,1 \\
TCT $(\mathrm{t} 2)-\mathrm{TCT}(\mathrm{t} 3)$ & & $-0,3$ \\
$\mathrm{TCT}(\mathrm{t} 0)-\mathrm{TCT}(\mathrm{t} 2)$ & $*$ & $-0,3$ \\
$\mathrm{TCT}(\mathrm{t} 2)-\mathrm{TCT}(\mathrm{t} 4)$ & $*$ & 0,4 \\
$\operatorname{TCT}(\mathrm{t} 1)-\mathrm{TCT}(\mathrm{t} 2)$ & $*$ & $-0,4$ \\
$\mathrm{TCT}(\mathrm{t} 0)-\mathrm{TCT}(\mathrm{t} 3)$ & $*$ & $-0,6$ \\
$\mathrm{TCT}(\mathrm{t} 0)-\mathrm{TCT}(\mathrm{t} 4)$ & $*$ & 0,7 \\
$\mathrm{TCT}(\mathrm{t} 1)-\mathrm{TCT}(\mathrm{t} 3)$ & $*$ & $-0,7$ \\
$\mathrm{TCT}(\mathrm{t} 1)-\mathrm{TCT}(\mathrm{t} 4)$ & & $-0,8$ \\
\hline
\end{tabular}

- It indicates a significant difference.

Both Table 3 and Table 4 clearly show that from 2/5 of Movement Time (MT) added to each participant's Reaction Time on, the number of mistakes significantly grows. Specifically, the error ratio is greater than the success ratio from TCT ( $\mathrm{t} 2$ ) onwards, thus defining the threshold for PoNR. As mentioned above, TCT (tx) $(\mathrm{x}=0, . ., 4)$ for each player was defined as x/5 MT + RT (being MT, RT median values of such player.
Table 4. This table expresses success/error ratio between different experimental conditions.

\begin{tabular}{ccc}
\hline & Success ratio & Error ratio \\
\hline TCT $(\mathrm{t} 0)$ & 7 & 3 \\
TCT $(\mathrm{t} 1)$ & 8 & 2 \\
TCT $(\mathrm{t} 2)$ & 4 & 6 \\
TCT $(\mathrm{t} 3)$ & 1 & 9 \\
TCT $(\mathrm{t} 4)$ & 0 & 10 \\
\hline
\end{tabular}

\section{Discussion}

Reaction Time (RT) increased significantly affected by the uncertainty, which could mean that the (regional level expert) player/participant waits for the appearance of the second LED light; this result is in accordance with the rehearsal of Gutiérrez-Dávila et al. (2013a), however, TM does not change, which means that the participant does not change his/her passing technic, this result differs from the subsequent analysis (Gutierrez-Davila et al., 2013b) where MT is also increased. Moreover and subsequently, changes were also appreciated in RRT.

The fact that Reaction Time (RT) significantly increases contradicts Goh et al. (2014), when they say that when a person responds several times to a choice-reaction test, they often reduce their Reaction Time (RT).

This result contradicts the hypothesis of previous studies that uncertainty resulting from target change increases movement time (Borysiuk \& Waskiewicz, 2008; GutiérrezDávila et al., 2013; Sanderson, 1983).

RRT was not affected when the target change was delayed, which differs from Gutiérrez-Cruz et al. (2016), this can be explained by the fact that regional expert players participating in this study wait for the appearance of the second stimulus, so that neither RT nor MT will change.

There is strong evidence that when the target change was delayed, errors strongly increase in accordance with Gutiérrez-Cruz et al. (2016); being clearly defined the point of no return from CRT(t2) onwards as it is showed in Table 3, where significants differences between different experimental conditions are statistically compared.

This study has a large internal validity because of his laboratory condition where all variables are specifically controlled; while having as limitations that it was not possible to gather professional top (say ACB level) players for the study; moreover, despite it was slightly corrected trying to simulate as far as possible a real situation with projectors, the study design lost external validity because of the fact that was undertaken in a laboratory instead of in a real field.

The first part of the hypothesis was verified, when uncertainty increases, RT increases as well, which means that 
this relationship is equally valid for both, fencing and basketball.

However, the second part of the hypothesis was not completely verified: the RRT did not increase although the target change was delayed, which could be attributable to the fact that expert participants were waiting for the second LED light to turn on, despite the traps to avoid it; this is a new outcome taking into account that different sports are being discussed; in basketball pass, it does not occur as it occurs in fencing. This outcome does give more importance to this study as it generates new knowledge to the scientific community.

The part that was also fulfilled was that the errors significantly soared when the target change was delayed. In the light of these results, is it concluded that experienced (in general terms) players delay the start of the movement until the uncertainty ( $2^{\text {nd }}$ stimulus onset) is solved/gone, increasing as a result, the reaction time, and as a consequence, the response reaction time, but minimising the number of errors on the other hand

Therefore, players in learning phase should be emphasized not to rush when being about to make the pass but instead analyse the possibilities to clear up the uncertainty before actually executing it

Results clearly shows that point of no return is defined from 2/5 of Movement Time (MT) added to each participant's Reaction Time onwards.
This study has paved the groundwork for future studies to check if the twofold objectives analysed in this paper, are not only analysable but also trainable defining a method aiming at reducing the RRT under uncertainty as well as improving the ratio of errors in basketball pass as many authors suggest (Adelson, 1984; Iglesias et al., 2005; Kinrade, Jackson, $\&$ Ashford, 2015; Klein, Hintze, \& Saab, 2013; Nakamoto \& Mori, 2008; Pérez et al., 2008). While it is recognized that the basket pass in field conditions depends on a multiplicity of variables, experimental control in lab conditions makes it possible the analysis of each of these variables affecting the pass in an independent manner. Once the impact of the variables is known (by each one and among them), a global understanding is then possible. Therefore, the need for experimental control implied performing this research in laboratory conditions as the first step.

Further research should be performed in field conditions with real opponent to ensure the ecological validity of the study. This is a challenge for the future, and the technologies available should be improved so that the plastron can be replaced with a real opponent keeping the same experimental control.

Finally, it is rather advisable to incorporate as future participants' basketball players with a range of different levels of expertise (not only regional experienced players but also ACB, LEBs, EBA players as well as new, not particularly skilled players), to compare their performances against the tests.

\section{References}

1. Adelson, B. (1984). When novices surpass experts: The difficulty of a task may increase with expertise. Journal of Experimental Psychology: Learning, Memory, and Cognition, 10(3), 483-495. https://doi. org/10.1037/0278-7393.10.3.483

2. Borysiuk, Z., \& Waskiewicz, Z. (2008). Information Processes, Stimulation and Perceptual Training in Fencing. Journal of Human Kinetics, 19, 63-82. https://doi.org/10.2478/v10078-008-0005-y

3. Di Russo, F., Taddei, F., Apnile, T., \& Spinelli, D. (2006). Neural correlates of fast stimulus discrimination and response selection in top-level fencers. Neuroscience Letters, 408(2), 113-118. https://doi.org/10.1016/j. neulet.2006.08.085

4. Dodds, P., Griffin, L. L., \& Placek, J. H. (2001). Chapter 2. A Selected Review of the Literature on Development of Learners' Domain-Specific Knowledge. Journal of Teaching in Physical Education.

5. Galatti, L. R., Paes, R. R., Machado, G. V, \& Seoane, A. M. (2015). Campeonas del Mundo de Baloncesto: factores determinantes para el rendimiento de excelencia. / Basketball World Champions: determinant factor for excellence performance. Cuadernos de Psicología Del Deporte, 15(3), 187-192. Retrieved from http://search.ebscohost.com/login.aspx ?direct=true $\& \mathrm{db}=\mathrm{s} 3 \mathrm{~h} \& \mathrm{AN}=111376301 \&$ lang=pt-br\&site=ehost-live

6. Goh, H.-T., Gordon, J., Sullivan, K. J., \& Winstein, C. J. (2014). Evaluation of attentional demands during motor learning: validity of a dualtask probe paradigm. Journal of Motor Behavior, 46(2), 95-105. https:// doi.org/10.1080/00222895.2013.868337

7. Gutiérrez-Cruz, C., Rojas, F. J., \& Gutiérrez-Davila, M. (2016). Effect of defence response time during lunge in foil fencing. Journal of Sports Sciences, 34(7), 651-7. https://doi.org/10.1080/02640414.2015.1068434.
8. Gutiérrez-Dávila, M., Javier Rojas, F., Antonio, R., \& Navarro, E. (2013). Effect of uncertainty on the reaction response in fencing. Research Quarterly for Exercise and Sport, 84(1), 16-23. https://doi.org/10. 1080/02701367.2013.762286

9. Gutierrez-Davila, M., Rojas, F. J., Caletti, M., Antonio, R., \& Navarro, E. (2013). Effect of target change during the simple attack in fencing. J Sports Sci, 31(10), 1100-1107. https://doi.org/10.1080/02640414.2013.770908

10. Iglesias, D., Sanz, D., García-Calvo, T., Cervelló, E., \& Del Villar, F. (2005). Influencia de un programa de supervisión reflexiva sobre la toma de decisiones y la ejecucución del pase en jóvenes jugadores de baloncesto. Revista de Psicología Del Deporte, 14(2), 209-223.

11. Kinrade, N. P., Jackson, R. C., \& Ashford, K. J. (2015). Reinvestment, task complexity and decision making under pressure inbasketball. Psychology of Sport and Exercise, 20, 11-19. https://doi.org/10.1016/j.psychsport.2015.03.007

12. Klein, G., Hintze, N., \& Saab, D. (2013). Thinking inside the box: The ShadowBox method for cognitive skill development. Proceedings of the 11 Th International Conference on ..., (May). Retrieved from http:// scholar.google.com/scholar?hl=en\&btnG=Search\&q=intitle:Thinking+ Inside+the+Box:+The+ShadowBox+Method+for+Cognitive+Skill+Deve lopment\#0

13. McGarry, T., \& Franks, I. M. (2003). On the nature of stopping an earlier intended voluntary action. Motor Control, 7(2), 155-98. Retrieved from http://www.ncbi.nlm.nih.gov/pubmed/13679628

14. Muggleton, J. M., \& Brennan, M. J. (2010). An assessment of laser vibrometry for the measurement of ground vibration. Retrieved from https://eprints.soton.ac.uk/160683/ 
15. Nakagawa, S., \& Cuthill, I. C. (2007). Effect size, confidence interval and statistical significance: A practical guide for biologists. Biological Reviews. https://doi.org/10.1111/j.1469-185X.2007.00027.x

16. Nakamoto, H., \& Mori, S. (2008). Sport-specific decision-making in a Go/NoGo reaction task: difference among nonathletes and baseball and basketball players. Perceptual and Motor Skills, 106(1), 163-70. https://doi.org/10.2466/pms.106.1.163-170

17. Nunes, H., Iglesias, X., Daza, G., Irurtia, A., Caparrós, T., \& Anguera, M. T. (2016). Influencia del pick and roll en el juego de ataque en baloncesto de alto nivel. Cuadernos de Psicologia Del Deporte, 16(1), 129-142.

18. Oliver, D. (2006). Basketball on Paper: Rules and Tools for Performance Analysis. Journal of Sport Management, 20, 120-123.

19. Osman, A., Kornblum, S., \& Meyer, D. E. (1986). The point of no return in choice reaction time: Controlled and ballistic stages of response preparation. Journal of Experimental Psychology: Human Perception and Performance, 12(3), 243-258. https://doi.org/10.1037/00961523.12.3.243

20. Pérez, L., Iglesias, J., \& Mendes, R. (2008). El estudio del desarrollo motor: Entre la tradición y el futuro. Revista Fuentes, 8, 243-258. https://doi.org/10.1017/CBO9781107415324.004

21. Sanderson, F. (1983). The effect of directional uncertainty on reaction time and movement time in a fencing task. Journal of Sports Sciences, 1(2), 105-110. https://doi.org/10.1080/02640418308729667

22. Schmidt, R. A., \& Lee, T. D. (2011). Motor Control and Learning: a Behavioral Emphasis. Champaign, Illinois: Human Kinetics. 